\title{
Ireland's Tidal Energy Resource: an Assessment of a Site in the Bulls Mouth and the Shannon Estuary Using Measured Data
}

Fergal O'Rourke

Dundalk Institute of Technology, fergal.orourke@dkit.ie

Fergal Boyle

Technological University Dublin, fergal.boyle@tudublin.ie

Anthony Reynolds

Technological University Dublin, anthony.reynolds@tudublin.ie

Follow this and additional works at: https://arrow.tudublin.ie/engschmecart

Part of the Engineering Commons

\section{Recommended Citation}

O'Rourke,F.,Boyle, F. \& Reynolds, A. (2014) Ireland's tidal energy resource; An assessment of a site in the Bulls Mouth and the Shannon Estuary using measured data, Energy Conversion and Management, Vol. 87, pp. 726-734, ISSN 0196-8904, doi:10.1016/j.enconman.2014.06.089

This Article is brought to you for free and open access by the School of Mechanical and Design Engineering at ARROW@TU Dublin. It has been accepted for inclusion in Articles by an authorized administrator of ARROW@TU Dublin. For more information, please contact arrow.admin@tudublin.ie, aisling.coyne@tudublin.ie, gerard.connolly@tudublin.ie.

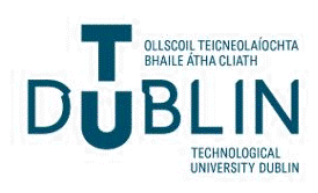




\title{
Ireland's tidal energy resource; an assessment of a site in the Bulls Mouth and the Shannon Estuary using measured data
}

\author{
Fergal O’Rourke ${ }^{\mathrm{a}, \mathrm{b},{ }^{*}}$, Fergal Boyle ${ }^{\mathrm{a}}$, Anthony Reynolds ${ }^{\mathrm{a}}$ \\ ${ }^{a}$ Department of Mechanical Engineering, Dublin Institute of Technology, Bolton Street, Dublin 1, Ireland \\ ${ }^{\mathrm{b}}$ Department of Electronic and Mechanical Engineering, Dundalk Institute of Technology, Dundalk, Co. Louth, Ireland
}

\begin{abstract}
The issues associated with Ireland's over reliance on fossil fuels to meet energy demands have sparked an interest in renewable energy. Renewable energy resources typically are intermittent and vary significantly in energy intensity. Tidal energy however has the advantage of predictability over large time scales and high power densities. A study of Ireland's tidal-current-energy resource has identified several viable sites. As part of this resource assessment, Acoustic Doppler Current Profilers were installed at two locations along Ireland's west coast, at a site in the Bulls Mouth and the Shannon Estuary. The Acoustic Doppler Current Profilers measured tidal current speed and direction at 30 minute intervals over a 30 day period at a range of depths through the water column. This is the first time the measured data appears in the literature as it has only recently been made public. This paper presents tidal current speed and direction, frequency of occurrence of speed, tidal roses at several depths through the water column, and a comparison of theoretical tidal-current-speed profiles with measured data for a site in the Bulls Mouth and in the Shannon Estuary. The paper compares power density at both sites over a lunar month and also proposes a best fit power law exponent with the measured data through the water column. Finally, the paper presents an energetic performance comparison for a tidal current turbine operating at both sites. The data presented in this paper can be used in the design process to estimate the hydrodynamic and structural performance of a tidal current turbine operating under real-life conditions. The data can also be used to assess different control strategies and to design a tidal current turbine to suit the site-specific characteristics.
\end{abstract}

\section{Contents}

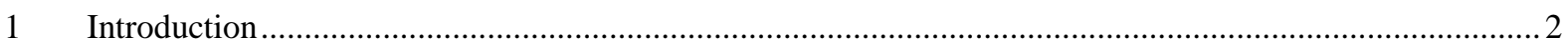

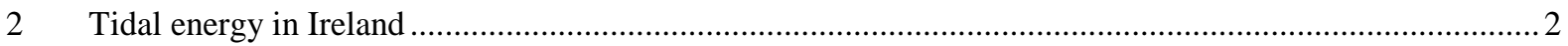

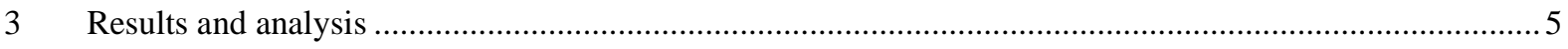

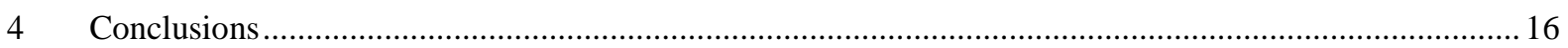

Keywords; Tidal current energy, assessment, Ireland, ADCP

\footnotetext{
* Corresponding author. Tel.:+353 429370200 (2695)

E-mail address: fergal.orourke@dkit.ie
} 


\section{Introduction}

Ireland's over dependence on the combustion of fossil fuels to meet energy demands has led to several energy related issues. These issues include security of supply, climate change, and fluctuating costs. The effect of the outlined issues has forced political leaders to consider alternative energy sources, and in particular renewable energies[1]. Most renewable energy sources are unpredictable in nature and vary significantly in intensity[2]. Tidal energy has the advantage of predictability over large time scales and, as a result, is an excellent choice as a base-load energy supply[3-5]. Recent research and development efforts in tidal energy extraction have been focused on tidalcurrent-turbine technology which utilises tidal currents; however, this technology is still at an early stage of development[6,7].

Sites where tidal-current-energy extraction is feasible are generally found along coastlines, inlets, channels and between headlands, as in these areas the tidal current speed is generally greater than tidal current speeds in the open ocean. When assessing the suitability of a site for tidal-current-energy extraction the tidal current speed is the main determinant[8]. The frequency of occurrence of speed is an excellent indicator as to the annual energy output which can be achieved.

A tidal-current-energy resource assessment was conducted for Ireland in 2004[9]. The assessment employed a 2-D numerical model for tidal current prediction, and by applying theoretical, technical, practical, accessible and viable limitations 11 sites were identified as viable for tidal-current-energy extraction. Some of the identified sites boast tidal current speeds close to $4 \mathrm{~m} / \mathrm{s}[10]$. Acoustic Doppler Current Profilers (ADCPs) were installed at two locations along Ireland's west coast, in the Bulls Mouth and the Shannon Estuary. The purpose of their installation was to validate the 2-D numerical model of the tidal current around Ireland only and, as a result, the measured data has only recently been made public.

This is the first time this measured data has appeared in the literature. This paper presents tidal current speed and direction, frequency of occurrence of speed, tidal roses at several depths through the water column and a comparison of theoretical tidal-current-speed profiles with measured data for both sites. An analysis of the measured data is also presented which includes a comparison of theoretical tidal current speed profiles with measured data, the power density and an energetic performance comparison. The data can be used in the design process to model the hydrodynamic and structural performance of a tidal-current-turbine design under real-life conditions. The data can also be used to assess the effect of different control strategies e.g. the use of pitch and yaw control. Also a tidal current turbine could be designed to suit the site-specific characteristics of the Bulls Mouth and the Shannon Estuary. The data may also be used for arranging the site-specific layout of tidal current turbines.

\section{Tidal energy in Ireland}

\subsection{Introduction}

Ireland is situated on the east of the Atlantic ocean with a coastline approximately $7500 \mathrm{~km}$ long[11, 12]. Along this coastline are numerous inlets and islands between which there are channels which are ideal for tidal-current-energy extraction due to the high tidal current speeds. Strong tidal currents are common along the north and east coasts and are particularly energetic entering the Irish Sea from the St. Georges Channel and the North Channel[10]. Figure 1 illustrates the oceans around Ireland and the direction of the flood[13-15]. The bathymetry and hydrography of Ireland's coastline 
influences the local tidal currents. The kinetic flux density is an excellent indicator of the tidal current energy resource available at a site which is proportional to the fluid density and the cube of its speed[16-19]. Therefore the speed is the most significant factor when deciding if a site is feasible for energy extraction[20-23]. Most of the tidalcurrent-flow research along the coastline to-date was done for the purpose of mapping fish species and spawning areas, and for the benefit of shipping. Relatively little work has been published in the interest of tidal-current-energy resource assessment.

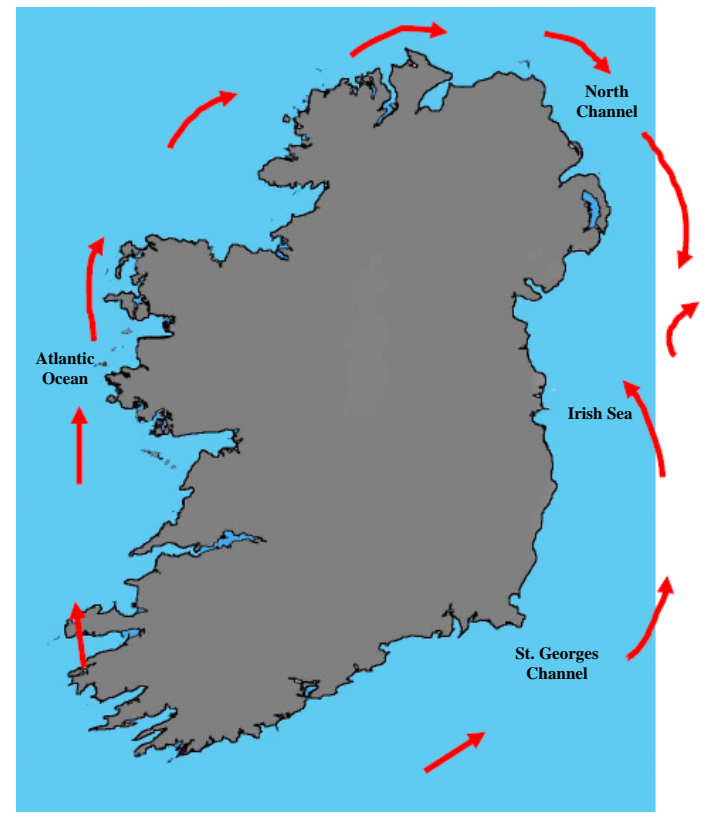

Figure 1. The oceans around Ireland and the

tidal current direction during a flood tidal movement[24]

\subsection{Resource assessment}

The currently-accepted tidal-current-energy resource assessment was completed by Sustainable Energy Authority Ireland (SEAI), an organisation set up by the Irish government with the objective of promoting the use of sustainable energy, and published in a report entitled Tidal and Current Energy Resources in Ireland in 2004. As part of this resource assessment, RPS Kirk McClure
Morton (UK), an engineering and environmental consultancy group, developed a 2-D numerical model of the tidal currents around Ireland. The numerical model was developed using Mike 21 software. Mike 21, developed by the Danish Hydrographic Institute, is an engineering software package designed for the simulation of fluid flows, waves, sediments and ecology in rivers, estuaries, seas and coastal regions. The 2-D numerical model predicted the tidal current surface speeds and was validated using measured data from two purposelyinstalled ADCPs. These were installed by AquaFact International Services Ltd, one at a site in the Bulls Mouth and the other at a site in the Shannon Estuary.

In the resource assessment the theoretical tidalcurrent-energy resource was first identified. This is the gross tidal energy content of the tidal current flow within a strip encircling Ireland. The landward boundary of the strip was taken at the point where the water depth reaches $10 \mathrm{~m}$ and the seaward boundary was taken at the 12 nautical mile territorial limit from the coast. Within this strip the numerically-predicted peak spring-tide surface speeds were depth-averaged using a $1 / 7^{\text {th }}$ power law to calculate the mid-depth tidal-current speeds. The mean tidal-current power, $\mathrm{P}_{\text {mean }}$, per unit area was then calculated using[25]

$$
\mathrm{P}_{\text {mean }}=\frac{1}{2} \rho \mathrm{K}_{\mathrm{s}} \mathrm{K}_{\mathrm{n}} \mathrm{U}_{\text {peak }}^{3} \quad\left(\mathrm{Wm}^{-2}\right)
$$

where $\rho$ is the density of seawater, $K_{s}$ is the speed availability factor $(0.424), \mathrm{K}_{\mathrm{n}}$ is the neap/spring factor (0.57) and $U_{\text {peak }}$ is the peak spring-tide middepth speed.

In order to calculate the theoretical extractable tidal-current energy, a turbine power coefficient, $\mathrm{C}_{\mathrm{P}_{\max }}$, of 0.59 , a turbine spacing array layout and a turbine cross-sectional area based on the depth of 
the water column were applied. The turbine spacing array layout assumed a lateral spacing of five diameters and an upstream/downstream spacing of 10-20 diameters. The diameter of the rotor was assumed to be 0.7 times the depth of the water column. The theoretical tidal-current-energy resource amounted to $230 \mathrm{TWh} / \mathrm{y}$. The technical tidal-current-energy resource was assessed by applying technical limitations to the theoretical resource. A turbine efficiency of 0.39 was applied and locations with tidal current speeds below 1.5 $\mathrm{m} / \mathrm{s}$ were excluded[24]. It was assumed that tidal current energy technology will not operate effectively at tidal current speeds below $1.5 \mathrm{~m} / \mathrm{s}$. The technical tidal-current-energy resource was calculated as $10.46 \mathrm{TWh} / \mathrm{y}$. The practical tidalcurrent-energy resource was subsequently obtained by applying practical limitations to the technical tidal-current-energy resource. Only sites with a water depth of between 20-40 m were included in the resource assessment, while areas such as shipping lanes and restricted areas were excluded. After the application of the practical limitations 11 sites remained and are shown in Figure 2[26]. The practical tidal-current-energy resource amounted to 2.633TWh/y. The accessible tidal-current-energy resource was calculated by applying accessible limitations to the practical tidal-current-energy resource. The accessible tidal-current-energy resource limitations had no effect on the practical tidal-current-energy resource and, as a result, the accessible tidal-current-energy resource also amounted to $2.633 \mathrm{TWh} / \mathrm{y}$. The viable tidalcurrent-energy resource is the resource obtained after applying commercial limitations to the accessible tidal-current-energy resource. In order to calculate the viable tidal-current-energy resource an economic model developed by Marine Current Turbine Ltd was used. The economic model calculated the optimum size of a turbine for a site based on water depth, tidal current speed, turbine costs, etc. From this model the viable tidal-currentenergy resource was estimated at $0.915 \mathrm{TWh} / \mathrm{y}[24]$.

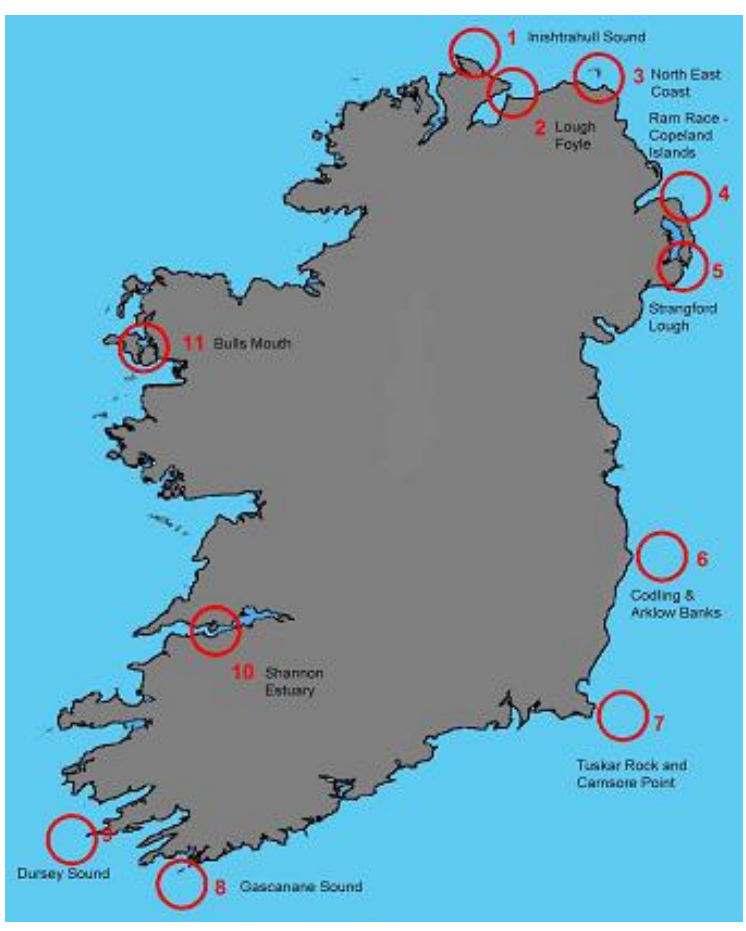

Figure 2. Location of the 11 sites identified in the practical tidal-current-energy resource assessment for Ireland including the two sites at which measurements were made: the Bulls

Mouth and the Shannon Estuary[24]

\subsection{Measurement instrumentation and site description}

A Teledyne RDI, Workhorse Sentinel $600 \mathrm{kHz}$ ADCP was used to measure the tidal current speed and direction[27]. The accuracy of the ADCP measured speed is $\pm 0.003 \mathrm{~m} / \mathrm{s}$ and the default speed range is $\pm 5 \mathrm{~m} / \mathrm{s}$ up to a maximum of $\pm 20 \mathrm{~m} / \mathrm{s}$. The number of cell depths available range from 1-255 with a ping rate of up to $10 \mathrm{~Hz}$. The compass (fluxgate type) includes a built-in field calibration feature and has an accuracy of $\pm 2^{\circ}$; however, this accuracy can be improved to $< \pm 1^{\circ}$ after calibration.

ADCPs were installed by AquaFact International Services Ltd at two locations on Ireland's west 
coast, at a site in the Bulls Mouth and at a site in the Shannon Estuary. The Bulls Mouth and Shannon Estuary are shown in Figure 2. Table 1 gives information on the two ADCPs' location and their installation period. Both sites have a water depth of approximately $14 \mathrm{~m}$. The seabed at both sites is relatively flat, consisting of rough sand with the occasional larger boulder scattered over the seabed. The ADCPs were bottom frame mounted and hardwired to a monitoring station which recorded the data. The ADCPs measured tidal current speed and direction at 30 minutes intervals over a 30 day period. Tidal-current-speed and direction data was recorded from a depth of two to 10 metres in one-metre depth intervals. Measurements were not made outside of this interval. Once the ADCP was retrieved, the binary data was processed using the RDI software WinADCP in order to output the speed and direction of the tidal currents.

\begin{tabular}{llll}
\hline Site & Latitude & Longitude & Installation Period \\
& $(\mathbf{d e g} \mathbf{N})$ & $(\mathbf{d e g} \mathbf{W})$ & \\
\hline Bulls Mouth & $54^{\circ} 00.598^{\prime}$ & $9^{\circ} 55.204^{\prime}$ & $25^{\text {th }}$ June $2004-27^{\text {th }}$ July 2004 \\
\hline Shannon Estuary & $52^{\circ} 35.656^{\prime}$ & $9^{\circ} 31.308^{\prime}$ & $24^{\text {th }}$ June 2004 $-28^{\text {th }}$ July 2004 \\
\hline
\end{tabular}

Table 1. Location of the two ADCPs along Ireland's west coast and their installation period

\section{Results and analysis}

\subsection{Tidal current speed}

Figure 3 and Figure 4 show the variation of the mid-depth tidal-current speed over a lunar month for a site in the Bulls Mouth and in the Shannon Estuary respectively. The overall variation of tidal current speed with respect to time is important when accessing the availability of tidal energy during daily periods. The two sites experience contrasting peak spring-tide speeds. A peak springtide speed of $1.01 \mathrm{~m} / \mathrm{s}$ was recorded at the site in the Bulls Mouth over the lunar month in comparison with a peak spring-tide speed of 2.02 $\mathrm{m} / \mathrm{s}$ at the site in the Shannon Estuary. Comparing both sites, it can be seen that the site in the Shannon Estuary is much more attractive for tidalcurrent-energy extraction.

Figure 5 and Figure 6 show both the tidal current speed and direction at mid-depth of the water column in the Bulls Mouth at spring and neap tide respectively. Figure 7 and Figure 8 show the corresponding data for the site in the Shannon Estuary. The speed and direction at the site in the Bulls Mouth vary significantly throughout the duration of spring and neap tide. Comparing the site in the Bulls Mouth with the site in the Shannon Estuary, it can be seen that the tidal current speed and direction in the Shannon Estuary are much more predictable.

For both sites, there is a notable difference in the tidal current speeds over the spring/neap cycle. The tidal cycle of the Shannon Estuary and the Bulls Mouth are dominated by the principal M2 and S2 tidal constituents [28]. As a result, the power generated by a tidal current turbine will vary significantly between spring tide and neap tide and on a daily basis between the peak tidal flow and slack water. Power averaging is often used to remove the daily tidal current speed variation. The 
power averaging approach given in [17] can be used to find the maximum average power that can be extracted for a tidal channel which is driven by multiple tidal constituents.

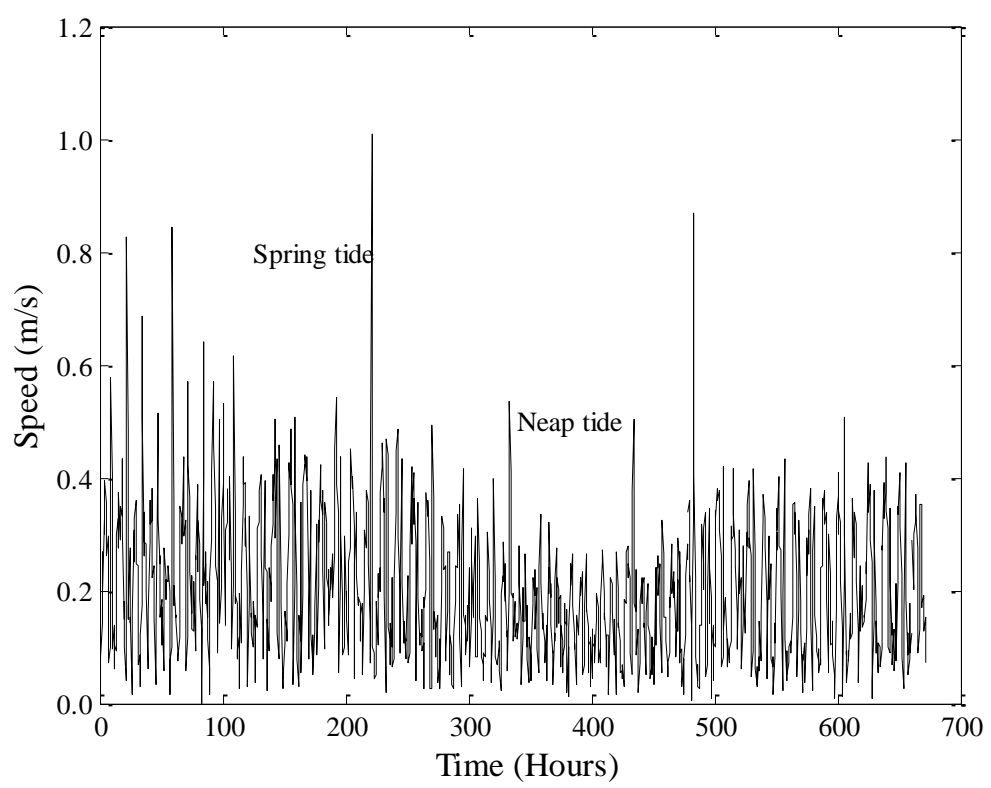

Figure 3. Measured tidal-current speed at mid-depth of the water column over a lunar month for a site in the Bulls Mouth

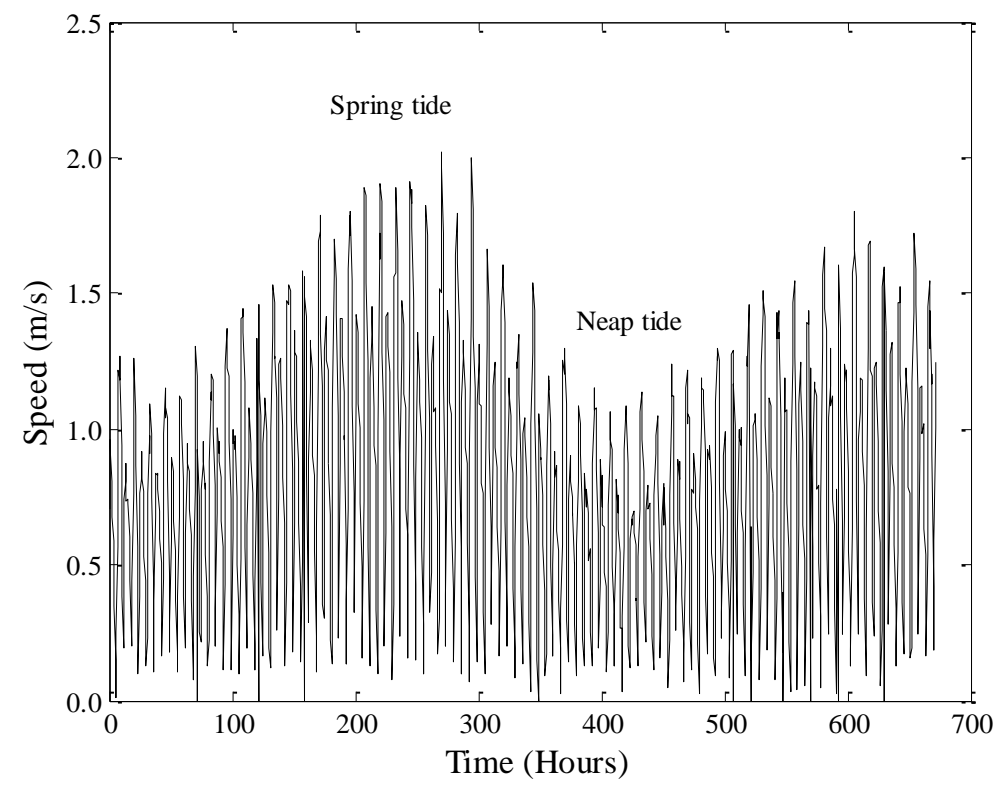

Figure 4. Measured tidal-current speed at mid-depth of the water column over a lunar month for a site in the Shannon Estuary 

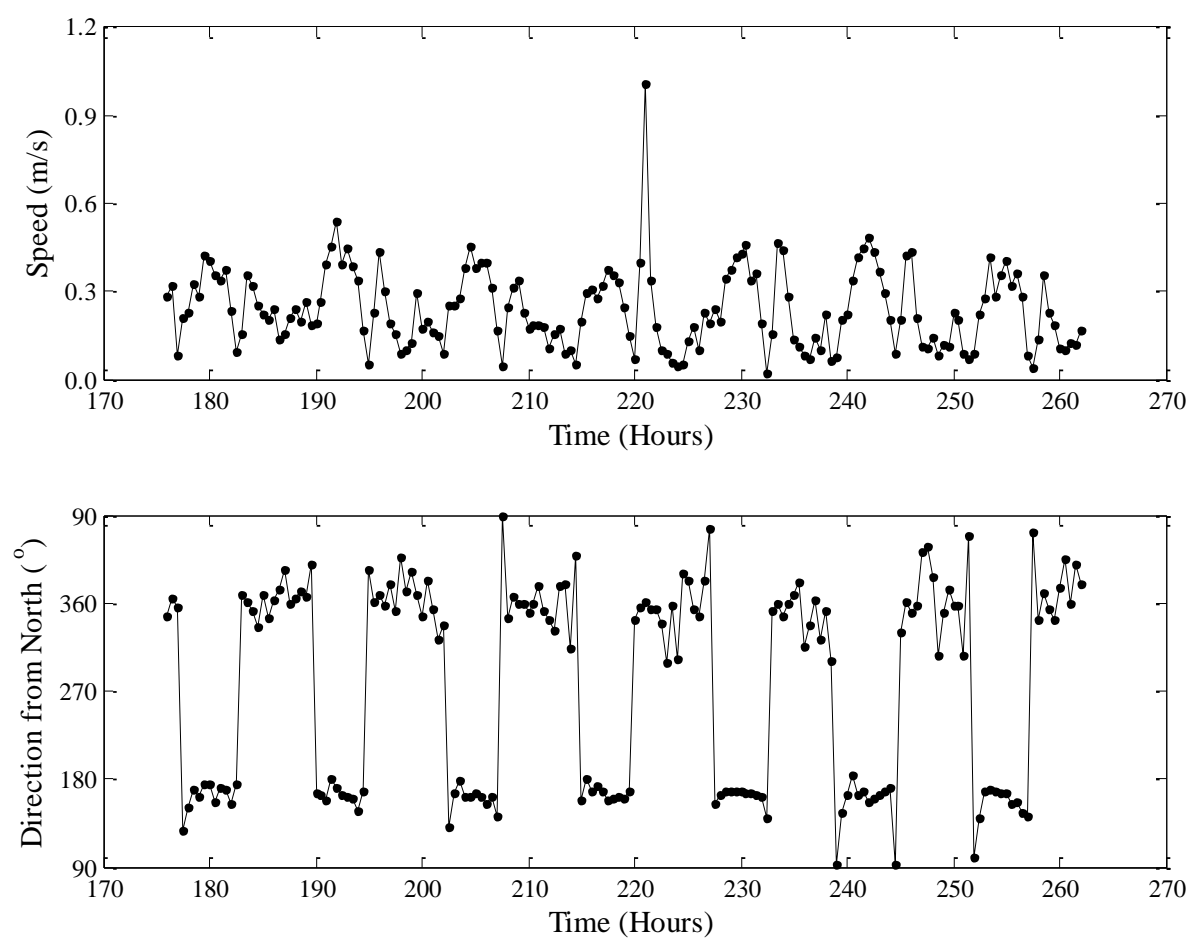

Figure 5. Measured tidal-current speed and direction at mid-depth of the water column at spring tide for a site in the Bulls Mouth
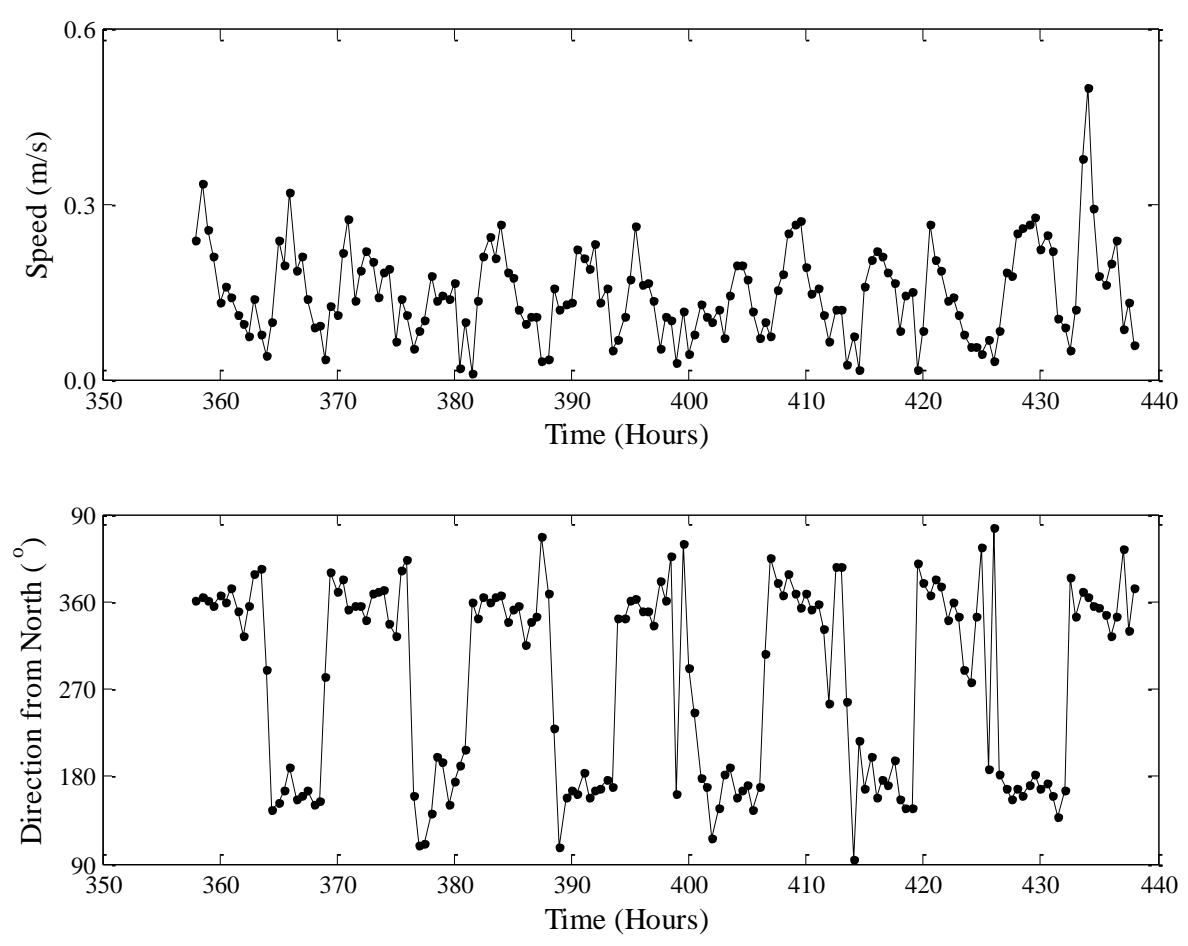

Figure 6. Measured tidal-current speed and direction at mid-depth of the water column at neap tide for a site in the Bulls Mouth 

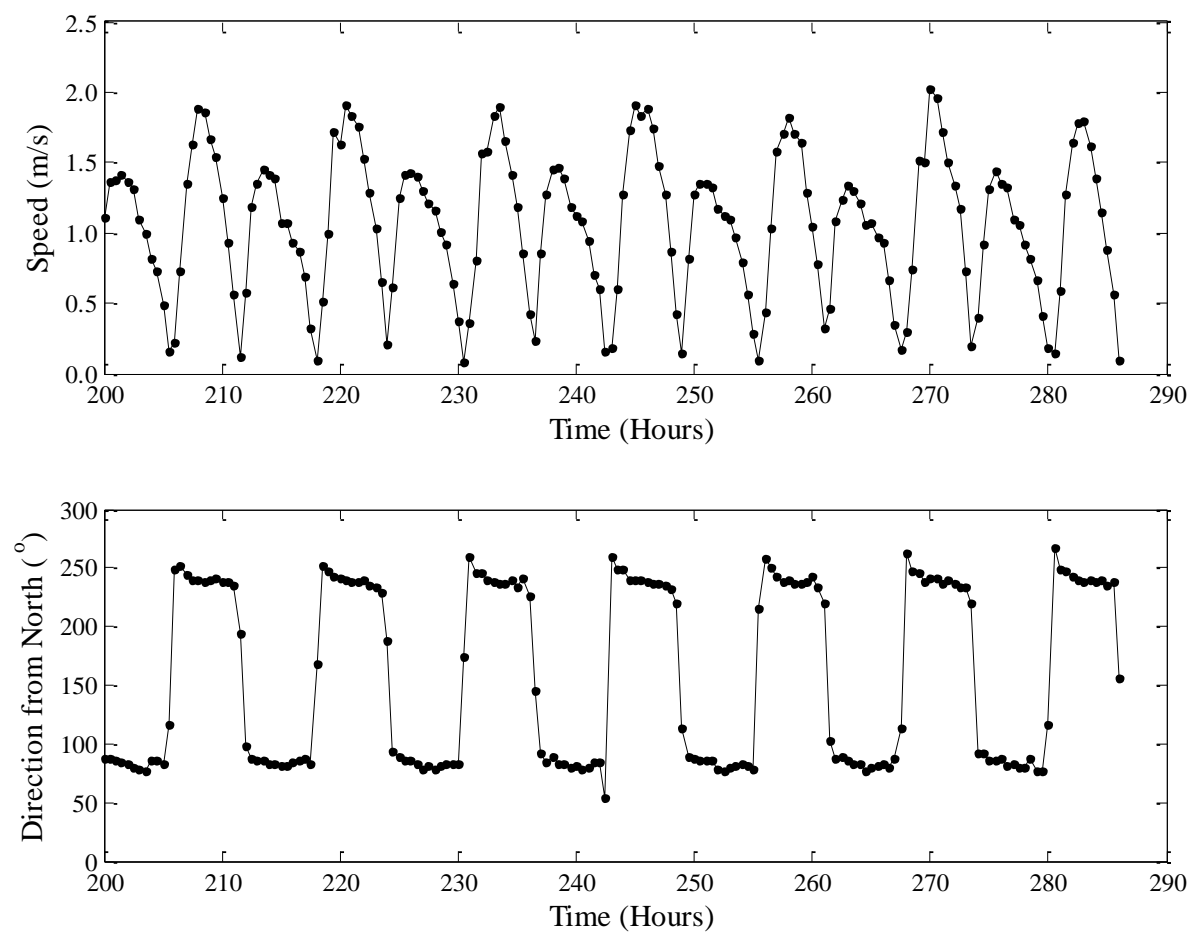

Figure 7. Measured tidal-current speed and direction at mid-depth of the water column at spring tide for a site in the Shannon Estuary
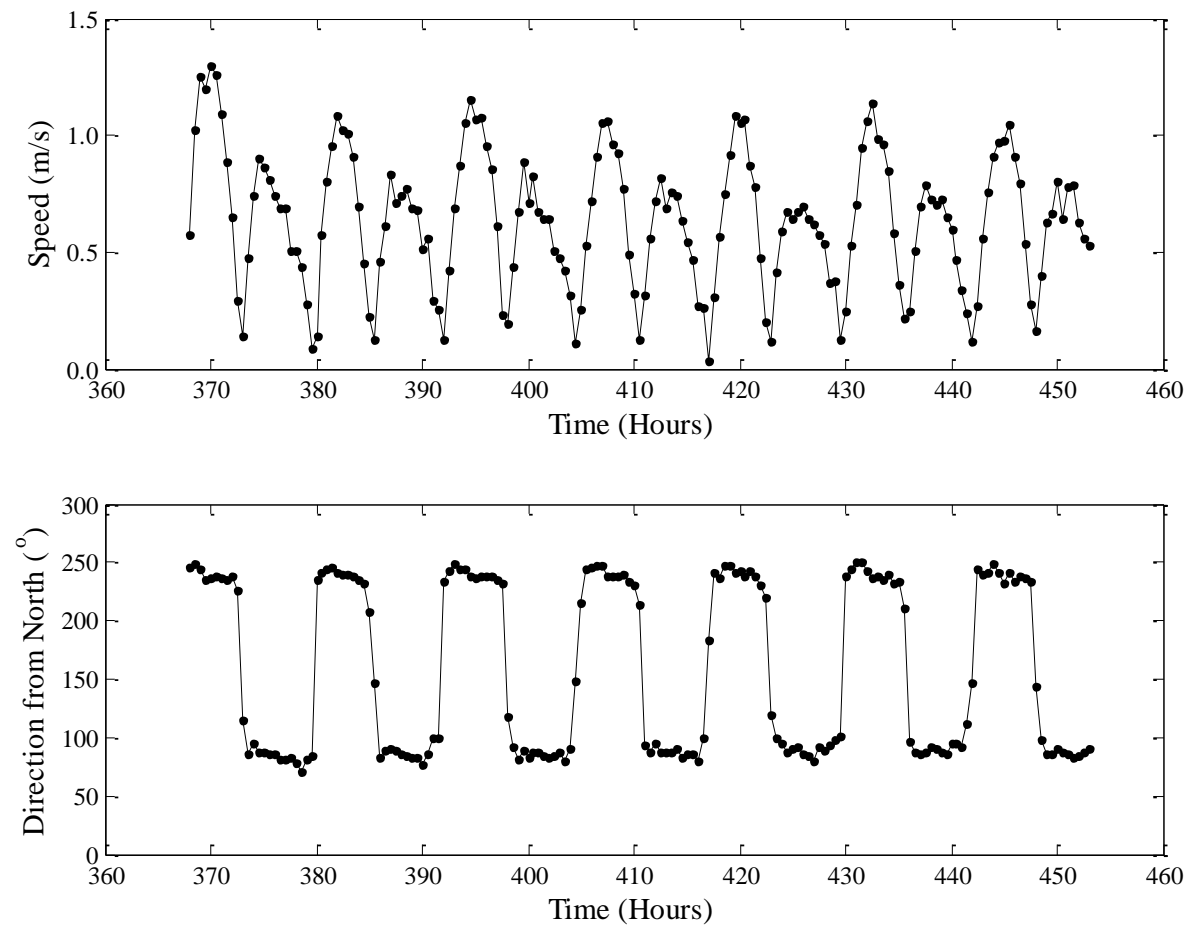

Figure 8. Measured tidal-current speed and direction at mid-depth of the water column at neap tide for a site in the Shannon Estuary 


\section{2 \\ Tidal-current-speed \\ frequency \\ of occurrence}

A frequency distribution analysis was conducted on the measured tidal-current-speed data for the two sites to obtain an understanding of the size of energy resource. The results of this analysis are presented in Figure 9 and Figure 10 where the frequency of occurrence of mid-depth speed over a lunar month for a site in the Bulls Mouth and the Shannon Estuary respectively are shown. It can be seen from the two histograms that the higher speeds occur more frequently at the site in the Shannon Estuary than at the site in the Bulls Mouth.

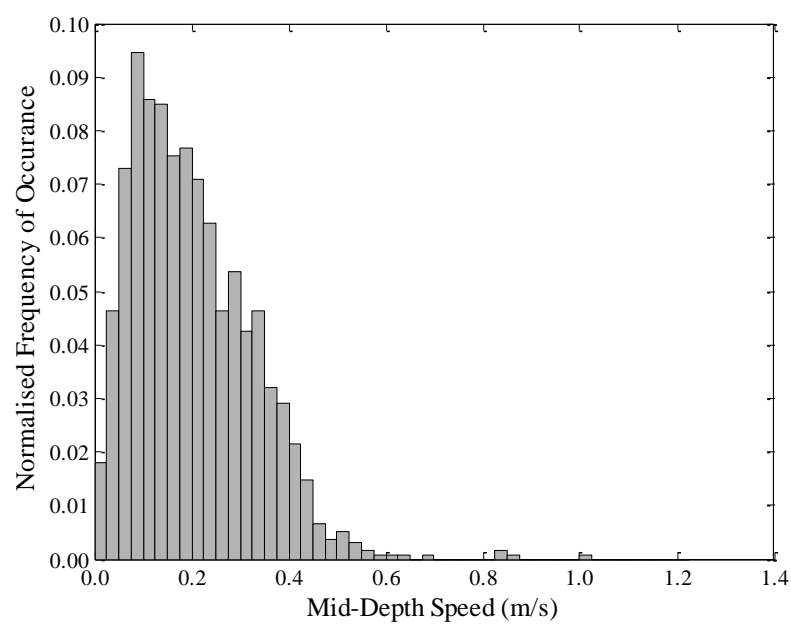

Figure 9. Frequency of occurrence of mid-depth speed over a lunar month for a site in the Bulls Mouth

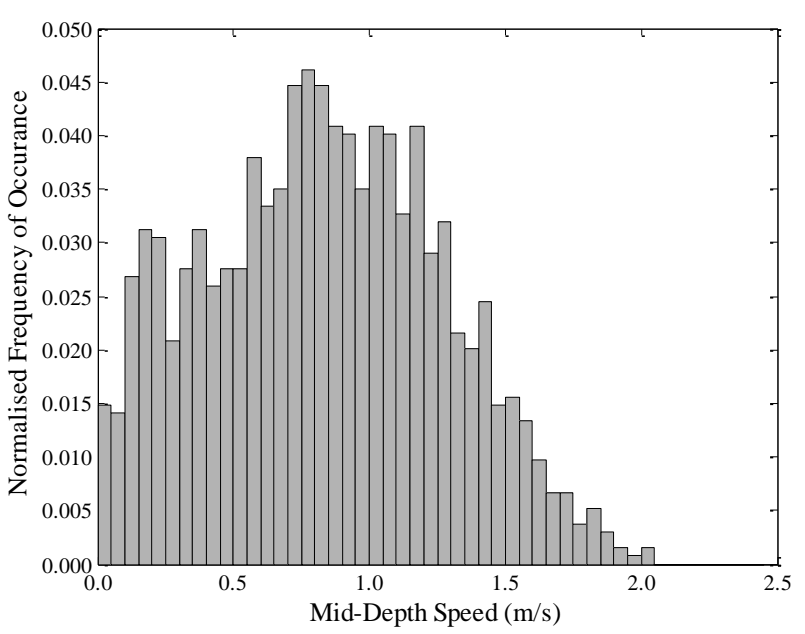

Figure 10. Frequency of occurrence of middepth speed over a lunar month for a site in the

\section{Shannon Estuary}

\subsection{Tidal roses}

In order to obtain a complete understanding of the tidal characteristics of a site tidal roses were created from the measured data at depths of two, four, six, eight and 10 metres for the site in the Bulls Mouth and the Shannon Estuary. A tidal rose provides information on the occurrence of a range of speeds and their corresponding flow directions. The circles drawn on the tidal roses show the frequency of occurrence of speed and direction of the tidal current. Figure 11 and Figure 12 illustrate the tidal roses for a site in the Bulls Mouth and the Shannon Estuary over a lunar month respectively. Figure 11 shows that the tidal current primarily flows from the north and south at the site in the Bulls Mouth. At this site the direction of the tidal currents stay relatively constant from the north and vary from the dominant south direction to a southsouth-east direction with an increase in depth. Figure 12 shows that the tidal current primarily flows from the east and the west-south-west at the site in the Shannon Estuary. Interestingly the directions of the tidal currents do not vary considerably through the depth of the water column over the lunar month. 

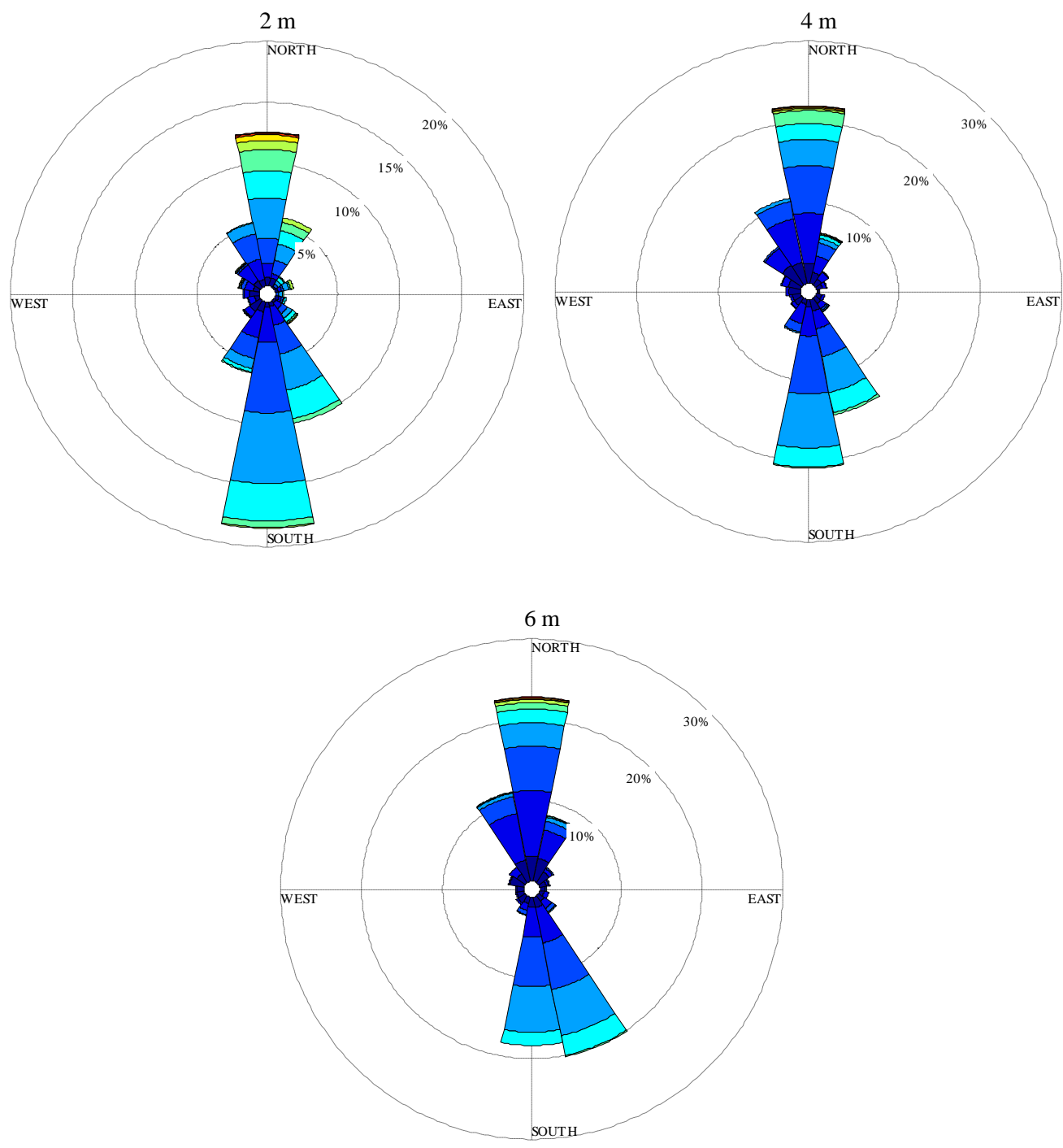

Speed $\mathrm{m} / \mathrm{s}$
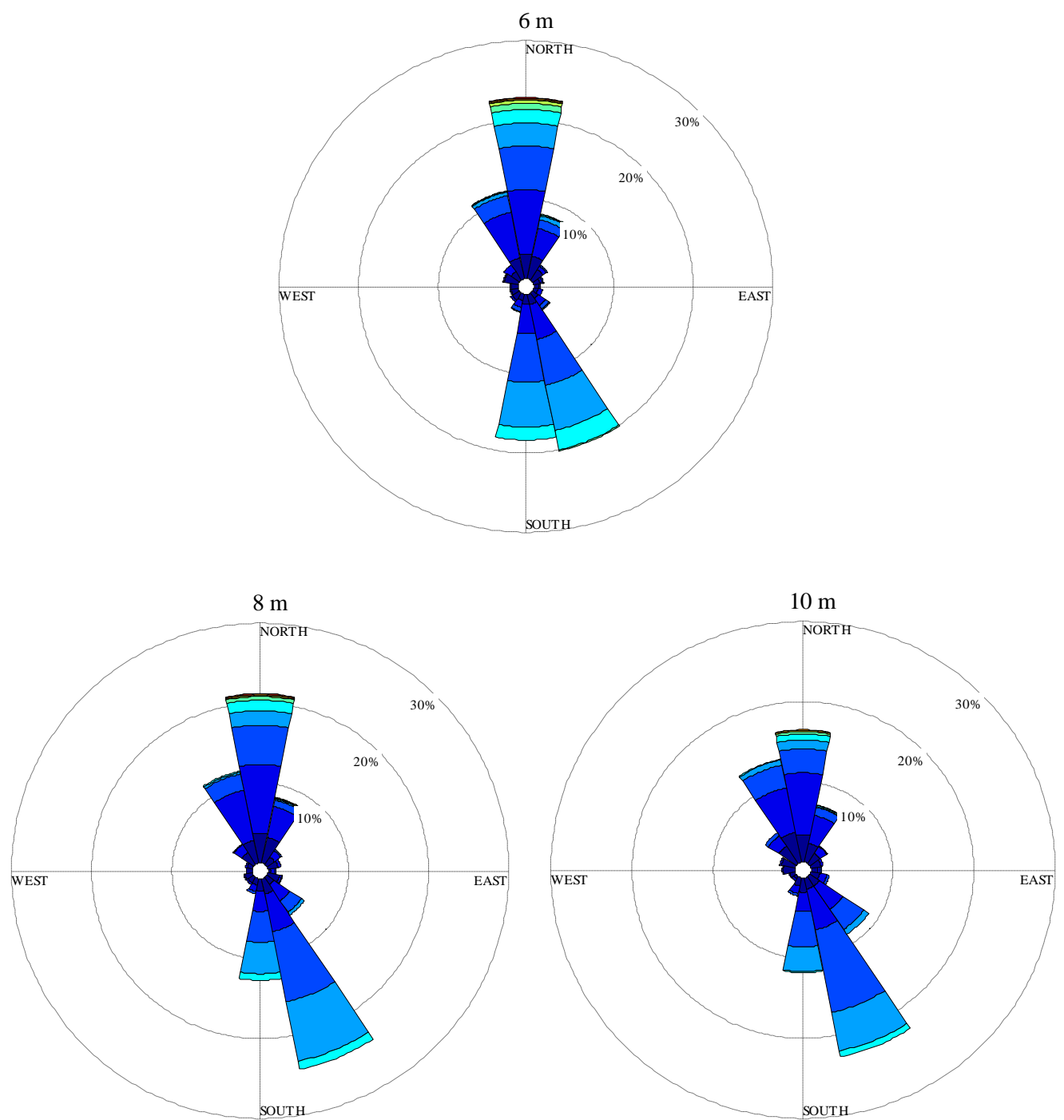

Figure 11. Tidal roses of measured tidal-current data over a lunar month at a site in the Bulls Mouth for five depths 

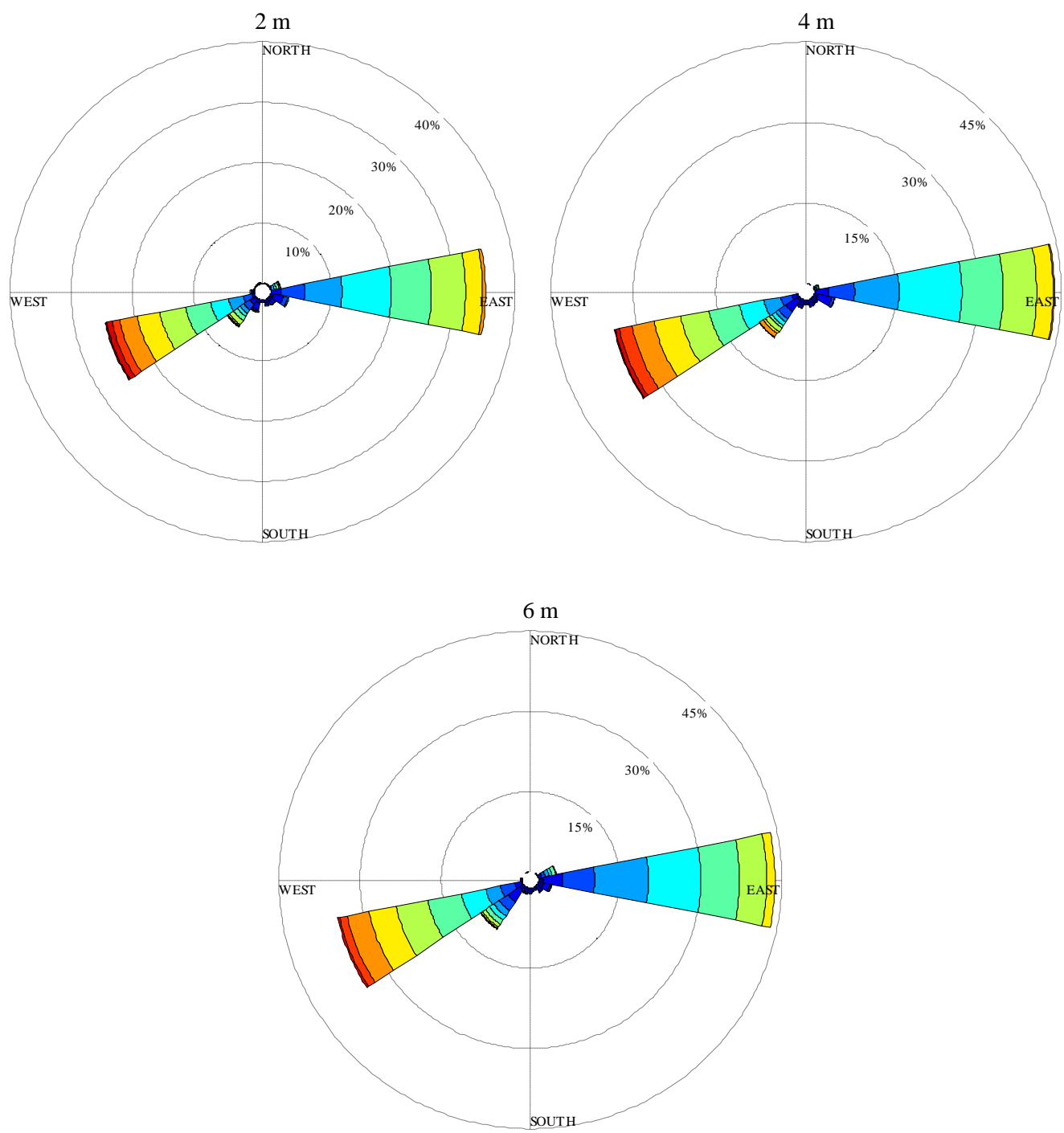

Speed $\mathrm{m} / \mathrm{s}$
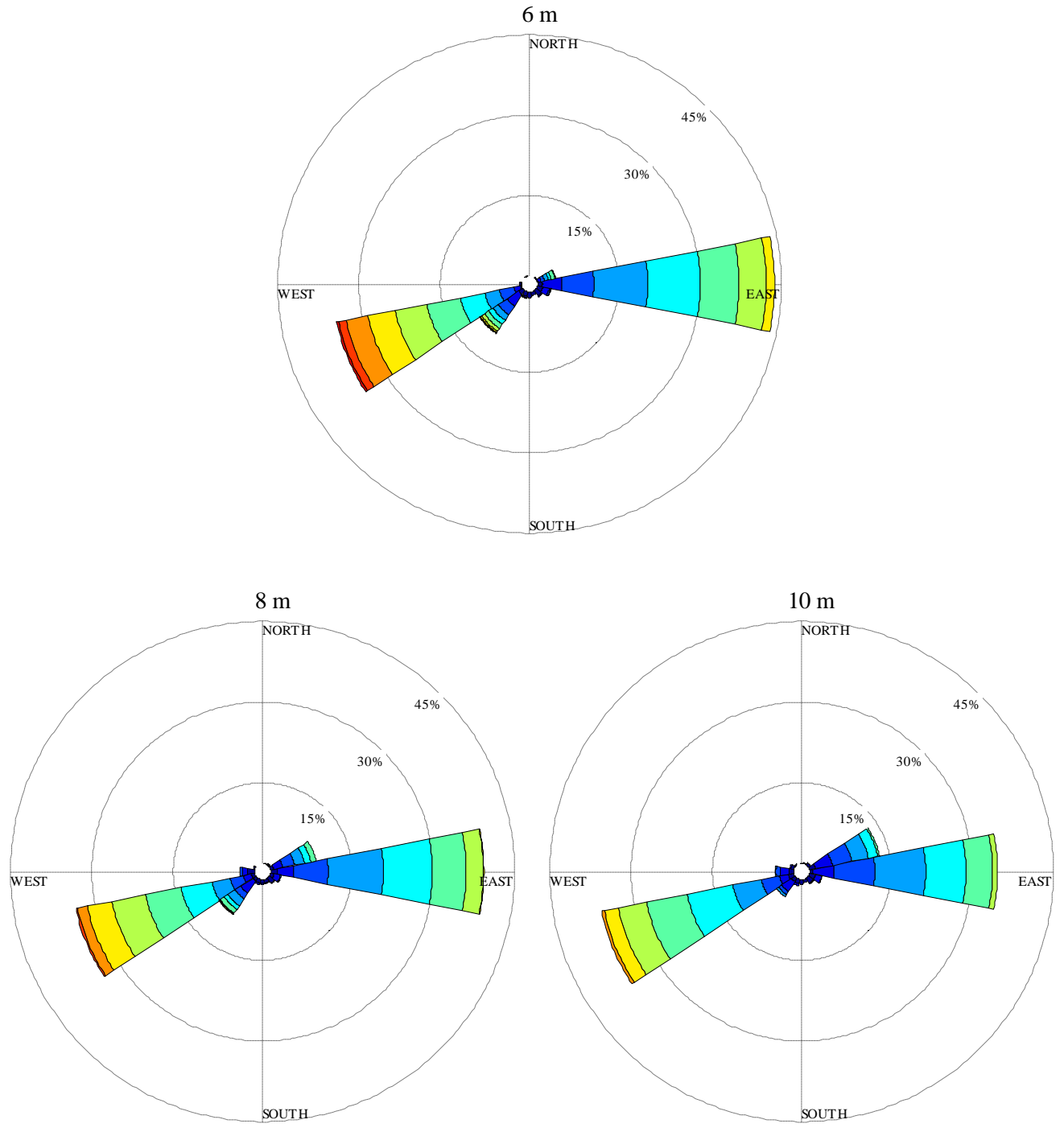

Figure 12. Tidal roses of measured tidal-current data over a lunar month at a site in the Shannon Estuary for five depths 


\subsection{Tidal-current-speed profiles}

Numerical simulations of the tidal current are often conducted to get a better understanding of the typical speeds which may occur at a particular site. These numerical simulations typically calculate the surface speed. The theoretical tidal-energy resource is then calculated using a power law or log law approximation to calculate the speed at the depth of interest in the water column. However, other approximations, given in [29], can be used to calculate the tidal current speed profile. The power law represents a rudimentary model for the variation in tidal current speed through the water column and is given as:

$$
\mathrm{u}(\mathrm{z})=\mathrm{u}_{\mathrm{z}_{\mathrm{r}}}\left(\frac{\mathrm{z}}{\mathrm{z}_{\mathrm{r}}}\right)^{\alpha}
$$

where $\mathrm{u}(\mathrm{z})$ is the tidal current speed, $z$ is the height above the seabed, $u_{\mathrm{z}_{\mathrm{r}}}$ is the reference tidal current speed, $z_{r}$ is the reference height above the seabed and $\alpha$ is the power law exponent. The exponent $\alpha$ can vary significantly from site-to-site. The main parameters which affect $\alpha$ are the tidal current speed and the seabed roughness, and several empirical methods can be used to calculate $\alpha$. A value of $1 / 7$ is a typical value for the power law exponent; however, this may not be a best fit for all sites. The speed profile can also be calculated using the log law:

$$
\mathrm{u}(\mathrm{z})=\mathrm{u}_{\mathrm{z}_{\mathrm{r}}}\left(\frac{\ln \left(\frac{\mathrm{z}}{\mathrm{z}_{0}}\right)}{\ln \left(\frac{\mathrm{z}_{\mathrm{r}}}{\mathrm{z}_{0}}\right)}\right)
$$

where the terms are as before and $\mathrm{z}_{0}$ represents the seabed roughness. Table 2 gives values for seabed roughness for various seabed conditions.

\begin{tabular}{lc}
\hline Seabed Description & Seabed Roughness, $\mathbf{z}_{\mathbf{0}}$ \\
& $(\mathbf{m m})$ \\
\hline Silt/sand & 0.02 \\
Sand/shell & 0.3 \\
Mud/sand/gravel & 0.3 \\
Mud/sand & 0.7 \\
Rippled sand & 6.0 \\
Mud & 0.2 \\
Sand/gravel & 0.3 \\
Unrippled sand & 0.4 \\
Gravel & 3.0 \\
\hline
\end{tabular}

Table 2. Seabed description and roughness for various seabed conditions[30]

Figure 13 and Figure 14 show a comparison of theoretical peak spring-tide and neap-tide speed profiles with measured data for a site in the Bulls Mouth respectively. The measured tidal-current speeds do not follow any theoretical speed profile and varies significantly through the water column. It can also be seen from both graphs that the $1 / 10^{\text {th }}$ power law fits closely to the log law using a seabed roughness of $\mathrm{z}_{0}=0.3 \mathrm{~mm}$ based on a seabed description of mud/sand/gravel. The importance of 
the measured tidal-current speed through the water column can be noted from Figure 13 and Figure 14, as the data does not follow any speed profile. The effect of the seabed roughness coupled with low tidal current speeds is shown to have a significant effect on the tidal current speeds throughout the water column. These effects must be considered when deciding on the suitability of a site for tidal current energy extraction. Therefore any estimations of the tidal-current-energy resource using a power law or log law may yield inaccurate values.

Figure 15 and Figure 16 show a comparison of theoretical peak spring-tide and neap-tide speed profiles with measured data for a site in the Shannon Estuary respectively. Comparing the different speed profiles with the measured tidalcurrent-speed data as shown in Figure 15, it can be seen that the measured speed data follow a power law profile with an exponent $\alpha=1 / 4$. Using the typical exponent value $\alpha=1 / 7$ will give an inaccurate tidal-current-energy resource assessment at this site. However, as shown in Figure 16, the measured data only follows a power law profile with an exponent $\alpha=1 / 4$ at a height above the seabed greater than $7 \mathrm{~m}$. Furthermore, the measured tidal current speeds below a $7 \mathrm{~m}$ height above the seabed do not follow a power law because of the interaction between the water and the seabed. This turbulent effect decreases with height above the seabed. For both sites, the log law profile with a value for seabed roughness of $\mathrm{z}_{0}=0.3$ $\mathrm{mm}$ based on a seabed description of mud/sand/gravel has shown to differ significantly from the measured data and as a result is not a good fit to estimate the speed distribution through the water column to achieve an accurate tidal-currentenergy resource assessment.

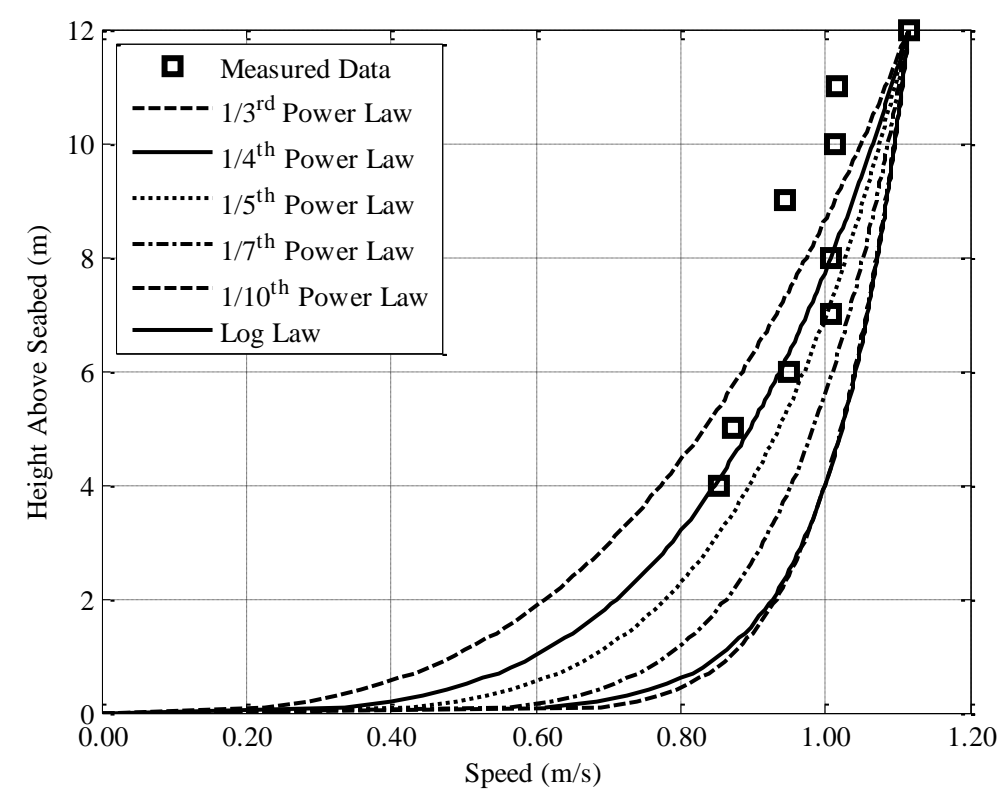

Figure 13. Comparison of theoretical peak spring-tide speed profiles with measured data at a site in the Bulls Mouth 


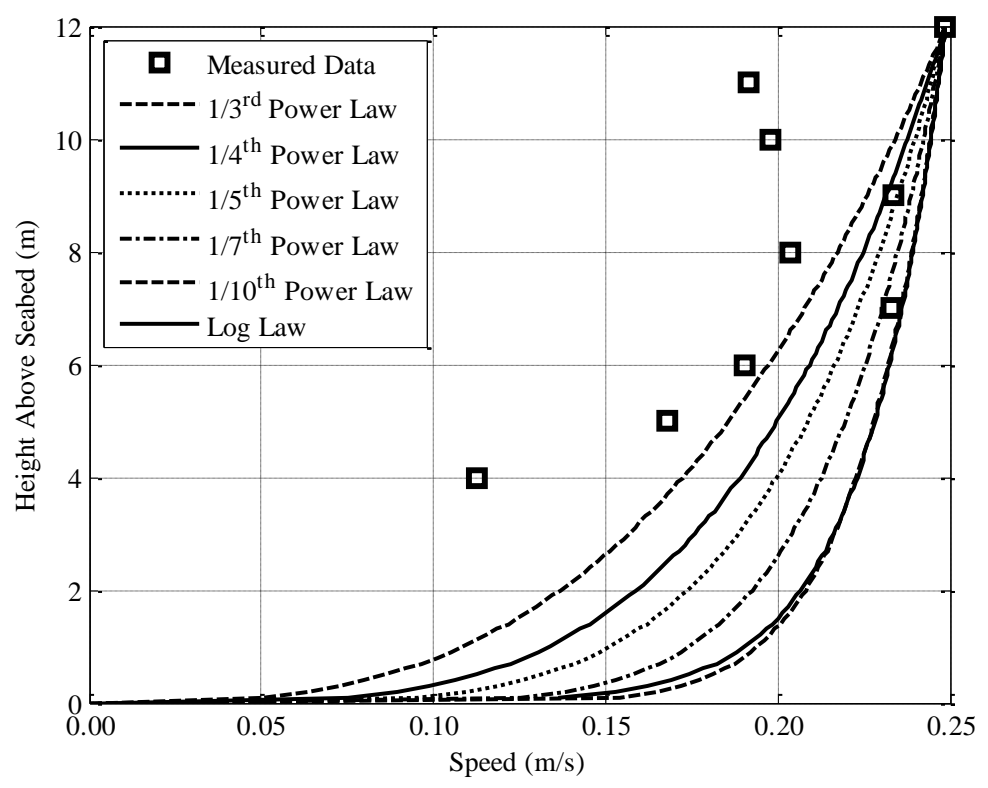

Figure 14. Comparison of theoretical neap-tide speed profiles with measured data at a site in the Bulls Mouth

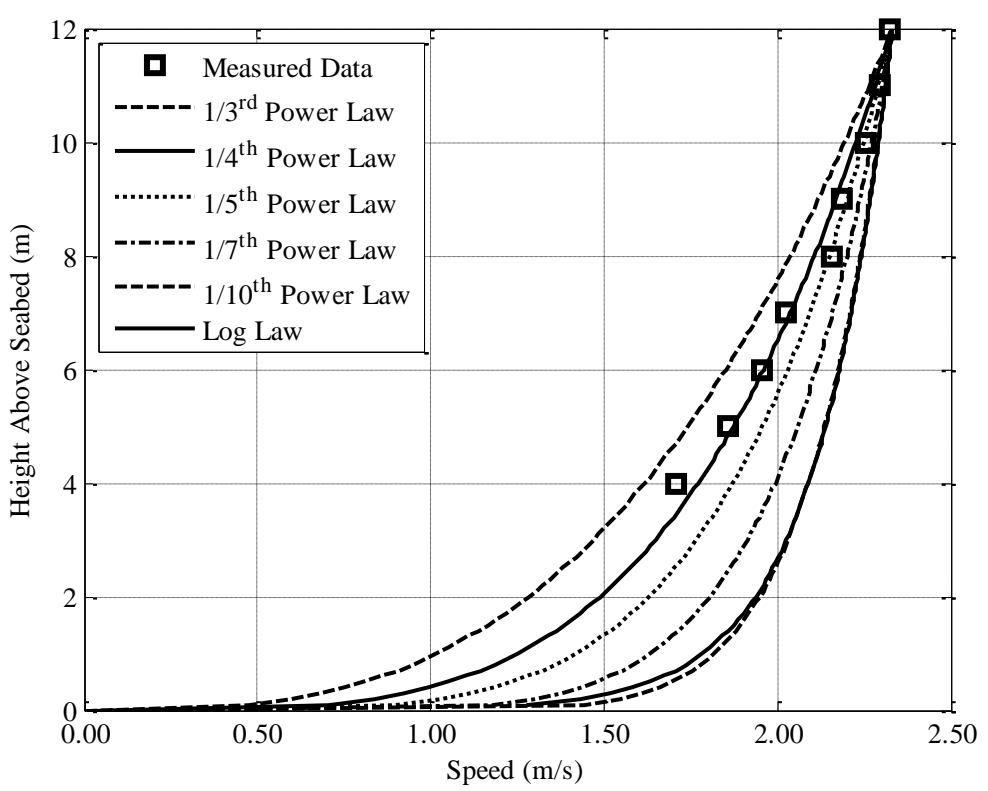

Figure 15. Comparison of theoretical peak spring-tide speed profiles with measured data at a site in the Shannon Estuary 


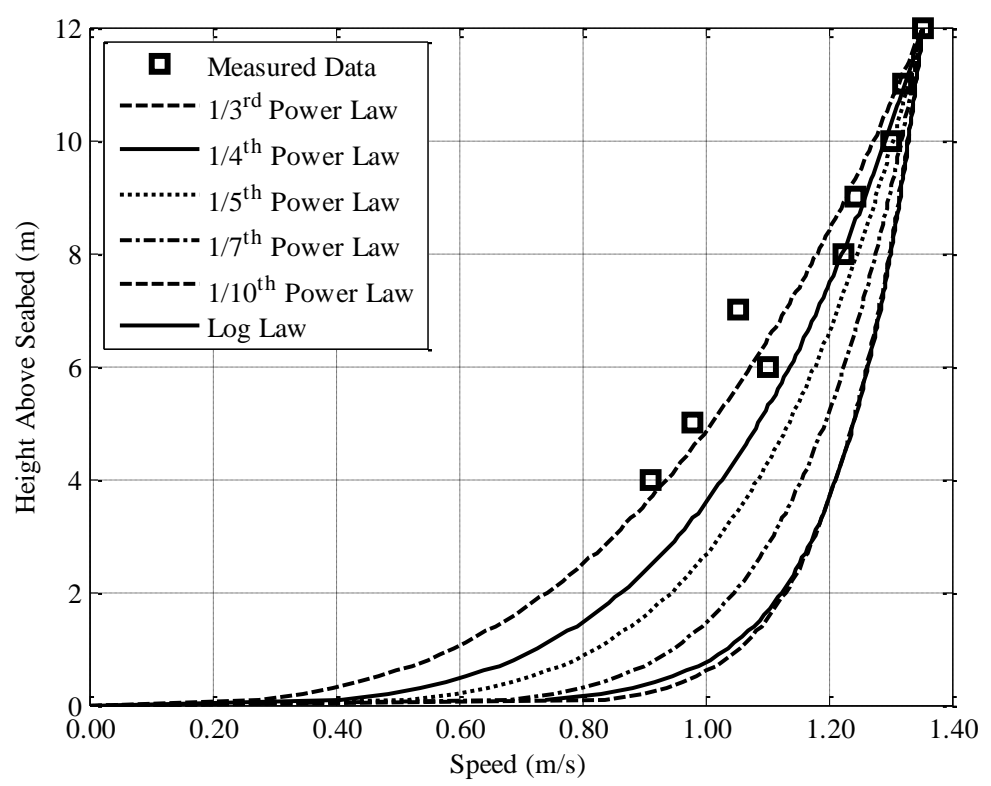

Figure 16. Comparison of theoretical neap-tide speed profiles with measured data at a site in the Shannon Estuary

\subsection{Power density}

Table 3 shows the mid-depth peak spring-tide speed, the mid-depth mean speed and the power density over a lunar month for both sites. The instantaneous power density, $\mathrm{P}_{\mathrm{A}}$, of a tidal current flow is calculated using

$$
\mathrm{P}_{\mathrm{A}}=\frac{1}{2} \rho \mathrm{U}^{3}
$$

where $\rho$ is the density of seawater and $U$ is the tidal current speed. Power density is often used as an indicator of tidal-current-energy hotspots[4]. The power density for each site was calculated by taking the mean of the distribution of instantaneous power densities. It is clear from Table 3 that the power density for the site in the Shannon Estuary is significantly greater than the power density for the site in the Bulls Mouth.

\begin{tabular}{llll}
\hline Site & $\begin{array}{l}\text { Mid-depth peak spring- } \\
\text { tide speed } \\
(\mathbf{m} / \mathbf{s})\end{array}$ & $\begin{array}{l}\text { Mid-depth mean } \\
\text { speed } \\
(\mathbf{m} / \mathbf{s})\end{array}$ & Power density \\
& 1.01 & 0.2 & 10 \\
\hline Bulls Mouth & 2.02 & 0.83 & 521 \\
\hline Shannon Estuary & & & \\
\hline
\end{tabular}

Table 3. Mid-depth peak spring-tide speed, mid-depth mean speed and power density over a lunar month for a site in the Bulls Mouth and in the Shannon Estuary

3.6 Tidal energy output comparison for the two sites

As described above, speed and direction measurements recorded at the Bulls Mouth and the
Shannon Estuary were used to determine the annual energy output of a tidal current turbine operating at each site. Table 4 illustrates the technical and operating data for the SERG tidal current turbine 
and the two sites. This analysis assumed that the tidal current turbine at each site had a fixed pitch and variable yaw design arrangement. Also, the rated speed and rated power of the tidal current turbine was varied to obtain the maximum annual energy output for each site[31, 32]. The analysis showed that, using the measured data and the SERG tidal current turbine technical specification, the annual energy output calculated from the site in the Shannon Estuary and the Bulls Mouth was 137.39 MWh and 2.16 MWh respectively. In order to gain a better understanding of the performance of a tidal current turbine operating at each site, the capacity factor for each site was calculated. The capacity factor is an excellent way to evaluate the energy performance of a tidal current turbine at a site. The capacity factor, $\mathrm{CF}$, is the ratio of the actual energy outputted by a tidal current turbine over a given period of time, typically one year, and the energy outputted by the tidal current turbine if it was to operate at its rated capacity for the same duration of time. The capacity factor is calculated using:

$$
\mathrm{CF}=\frac{\mathrm{E}}{\mathrm{T} \times \mathrm{P}_{\mathrm{r}}}
$$

where $\mathrm{E}$ is the energy outputted by the turbine over a given period of time, $T$, and $\mathrm{P}_{\mathrm{r}}$ is the rated power of the turbine[33, 34]. The values of annual energy output yielded a capacity factor of 0.12 and 0.19 for the site in the Bulls Mouth and Shannon Estuary respectively. These values indicate that the tidal current turbine captures less than $20 \%$ of the maximum available energy, based on the installed capacity, at both sites. However, varying the rated power of the tidal current turbine, while keeping the rotor diameter constant, will have an effect the capacity factor.

\begin{tabular}{lll}
\hline Site & Bulls Mouth & Shannon Estuary \\
\hline Rated Speed (m/s) & 0.5 & 1.75 \\
\hline Rated Power (kW) & 2 & 83 \\
\hline Hub Height (m) & 7 & 7 \\
\hline Rotor Diameter (m) & 10 & 10 \\
\hline Power Coefficient & 0.39 & 0.39 \\
\hline Power-Law Profile & $1 / 4$ & $1 / 4$ \\
\hline
\end{tabular}

Table 4. Technical data for the SERG tidal current turbine with fixed pitch and variable yaw [15, 35].

\section{Conclusions}

ADCPs were installed at two potential tidal-energy sites along Ireland's west coast and measured tidal current speed and direction at 30 minute intervals over a 30 day period. The site in the Shannon
Estuary has the greater tidal energy potential with maximum mid-depth speeds in excess of $2 \mathrm{~m} / \mathrm{s}$. The site in the Bulls Mouth experiences maximum speeds of approximately $1 \mathrm{~m} / \mathrm{s}$. A histogram displaying the normalised frequency of speed 
occurrence for both sites was presented. The two sites differ greatly when comparing the frequency of occurrence of speeds considered suitable for energy extraction. Tidal roses were produced at several depths of the water column for both sites, illustrating the frequency of occurrence of speeds and the direction in which they occur. The directions of the tidal currents in the Bulls Mouth stay relatively constant from the north and vary from the dominant south direction to a south-southeast direction with an increase in depth. The directions of the tidal currents in the Shannon Estuary stay relatively constant throughout the depth of the water column.

A comparison of theoretical tidal-current-speed profiles with measured data was conducted for both sites. To-date most tidal-current-energy assessments assume a $1 / 7^{\text {th }}$ power law to calculate the speed variation with depth. This methodology has been adopted from the wind industry. However, importantly, from the comparison conducted a $1 / 4^{\text {th }}$ power law is shown to provide a better fit to the measured data.

The mean power density was calculated for both sites. The results show a significant difference with the site in the Shannon Estuary having a power density significantly greater than the site in the Bulls Mouth with values of $521 \mathrm{Wm}^{-2}$ and $10 \mathrm{~W} / \mathrm{m}^{-}$ 2 respectively. Also an energetic performance comparison for a tidal current turbine operating at both sites was conducted showing significant difference. The annual energy output for the Shannon Estuary and the Bulls Mouth was 137.39 MWh and 2.16 MWh respectively. This corresponded to a capacity factor of 0.19 and 0.12 for the Shannon Estuary and the Bulls Mouth respectively.

Due to the deficiency of measured tidal-current data in the literature, the data presented in this paper is invaluable for the further development of tidal-current-energy technology. In particular, the data can be used in the numerical modelling of tidal current turbines. Furthermore, calculating the energy yields, capacity factors, forces and moments using the measured data will give the technology developer a better understanding of the materials and control strategy needed to maximise performance.

To further increase the depth of understanding of tidal current characteristics at a site such as turbulence, wave induced speeds, etc, higher frequency data recording is required. Recording speed and direction on a second basis rather than minute basis would yield the transient behaviour of the tidal current speed and direction. Important numerical-model inputs such as turbulence intensity could be calculated using real-life data and ultimately increase the accuracy of numerical predictions.

\section{Acknowledgments}

The authors greatly acknowledge AquaFact International Services Ltd, RPS Group Ltd and SEAI for their support and the use of collected data. The authors would also like to thank Mark Costelloe of AquaFact International Services Ltd for his help and useful discussions on the data.

\section{References}

1. O'Rourke, F., Boyle, F., Reynolds, A., Renewable energy resources and technologies applicable to Ireland. Renewable and Sustainable Energy Reviews, 2009. 13(8): p. 1975-1984.

2. Elliott, D., Renewable energy policy in the UK: Problems and opportunities. Renewable Energy. 9(1-4): p. 1308-1311.

3. Bryden, I.G., and Couch, S.J., ME1-Marine Energy Extraction: Tidal Resource Analysis. Renewable Energy, 2006. 31(2): p. 133-139.

4. Grabbe, M., Lalander, E., Lundin, S. and Leijon, M., A review of the tidal current 
energy resource in Norway. Renewable and Sustainable Energy Reviews, 2009. 13(8): p. 1898-1909.

5. Barbarelli, S., Amelio, M., Castiglione, T., Florio, G., Scornaienchi, N. M., Cutrupi, A., Lo Zupone, G., Analysis of the equilibrium conditions of a double rotor turbine prototype designed for the exploitation of the tidal currents. Energy Conversion and Management, 2014(0).

6. Ramos, V., Carballo, R., Sanchez, M., Veigas, M., Iglesias, G., Tidal stream energy impacts on estuarine circulation. Energy Conversion and Management, 2014. 80(0): p. 137-149.

7. Sarma, N.K., Biswas, A., Misra, R. D., Experimental and computational evaluation of Savonius hydrokinetic turbine for low velocity condition with comparison to Savonius wind turbine at the same input power. Energy Conversion and Management, 2014. 83(0): p. 88-98.

8. Li, Y., Lence, B.J. and Calisal, S.M., An integrated model for estimating energy cost of a tidal current turbine farm. Energy Conversion and Management, 2011. 52(3): p. 1677-1687.

9. O Rourke, F., F. Boyle, and A. Reynolds, Tidal energy update 2009. Applied Energy. 87(2): p. 398-409.

10. O'Rourke, F., Boyle, F., and Reynolds, A., Tidal current energy resource assessment in Ireland: Current status and future update. Renewable and Sustainable Energy Reviews, 2010. 14(9): p. 32063212.

11. Nairn, R., Ireland's Coastline: Exploring its Nature and Heritage. 2005: Collins Press. 220.

12. Neilson, B., and Costello, M.J., The Relative Lengths of Seashore Substrata Around the Coastline of Ireland as Determined by Digital Methods in a Geographical Information System. Estuarine, Coastal and Shelf Science, 1999. 49(4): p. 501-508.

13. Boyle, G., Renewable Energy Power for a Sustainable Future. Second Edition ed. 2004: Oxford University Press.

14. Charlier, R.H., A "Sleeper" Awakes: Tidal Current Power. Renewable and Sustainable Energy Reviews, 2003. 7(6): p. 515-529.

15. Bahaj, A.S., Molland, A.F., Chaplin, J.R., and Batten, W.M.J., Power and Thrust Measurements of Marine Current Turbines under various Hydrodynamic
Flow Conditions in a Cavitation Tunnel and a Towing Tank. Renewable Energy, 2007. 32(3): p. 407-426.

16. Adcock, T.A.A. The available power obtainable from tidal stream turbines from a flow around an idealised headland. in 3rd International Association for HydroEnvironment Engineering and Research Europe Congress. 2013. Porto.

17. Garrett, C., and Cummins, P., The power potential of tidal currents in channels. Proceedings of the Royal Society a Mathematical Physical and Engineering Sciences, 2005.

18. Garrett, C.a.C., P., The efficiency of a turbine in a tidal channel. Journal of Fluid Mechanics, 2007.

19. Houlsby, G.T., Draper, S., Oldfield, M., Application of linear momentum actuator disc theory to open channel flow 2008, Technical Report 2296-08 University of Oxford.

20. Palmer, J., The Tide is Turning. The New Scientist, 2008. 200(2677): p. 35-36.

21. Lemonis, G., and Cutler, J.C., Wave and Tidal Energy Conversion, in Encyclopedia of Energy. 2004, Elsevier: New York. p. 385-396.

22. Li, D., Wang, S., and Yuan, P., An overview of development of tidal current in China: Energy resource, conversion technology and opportunities. Renewable and Sustainable Energy Reviews, 2010. 14(9): p. 2896-2905.

23. Liu, H.-w., Ma, S., Li, W., Gu, H.-g., Lin, Y.-g., and Sun, X.-j., A review on the development of tidal current energy in China. Renewable and Sustainable Energy Reviews, 2011. 15(2): p. 1141-1146.

24. Sustainable Energy Ireland, Tidal \& Current Energy Resources in Ireland. 2004.

25. P.L. Fraenkel, Power from marine currents. Proceedings of the Institution of Mechanical Engineers, Part A: Journal of Power and Energy, 2002(216 (A1),): p. pp. 1-14. .

26. O'Rourke, F., Boyle, F. and Reynolds, A., Marine current energy devices: Current status and possible future applications in Ireland. Renewable and Sustainable Energy Reviews, 2010. 14(3): p. 10261036.

27. WorkHorse Monitor ADCP User's Guide, RD Instruments. 2001.

28. Adcock, T.A.A., Draper, S., Power extraction from tidal channels - Multiple 
tidal constituents, compound tides and overtides. Renewable Energy, 2014. 63(0): p. 797-806.

29. Soulsby, R., Dynamics of Marine Sands: A Manual for Practical Applications. 1997: Thomas Telford.

30. Hardisty, J., The Analysis of Tidal Stream Power. 2009: John Wiley and Sons.

31. Myers, L., Bahaj, A. S., Simulated electrical power potential harnessed by marine current turbine arrays in the Alderney Race. Renewable Energy, 2005. 30(11): p. 1713-1731.

32. Bahaj, A.S., Myers, L. E., Fundamentals Applicable to the Utilisation of Marine Current Turbines for Energy Production. Renewable Energy, 2003. 28(14): p. 22052211.

33. Ramos, V., and Iglesias, G., Performance assessment of Tidal Stream Turbines: A parametric approach. Energy Conversion and Management, 2013. 69(0): p. 49-57.

34. Carballo, R., Iglesias, G., A methodology to determine the power performance of wave energy converters at a particular coastal location. Energy Conversion and Management, 2012. 61(0): p. 8-18.

35. Batten, W.M.J., Bahaj, A.S., Molland, A.F., and Chaplin, J.R., The Prediction of the Hydrodynamic Performance of Marine Current Turbines. Renewable Energy, 2008. 33(5): p. 1085-1096. 